\title{
Improving staff's ability to work with challenging patient behaviours: An acute care approach
}

\author{
Nana Asomaning ${ }^{* 1}$, Rebecca Ramsden ${ }^{1}$, Kera Salvi ${ }^{1}$, Vishaka Keshav Chetram ${ }^{2}$ \\ ${ }^{1}$ Mount Sinai Hospital, University Avenue University, Toronto, ON, Canada \\ ${ }^{2}$ School of Public Health And Health Systems, University of Waterloo, Waterloo, ON, Canada
}

Received: July 9, 2015

Accepted: October 27, $2015 \quad$ Online Published: November 16, 2015

DOI: $10.5430 /$ jnep.v6n2p139

URL: http://dx.doi.org/10.5430/jnep.v6n2p139

\begin{abstract}
Background: Acute care healthcare professionals continue to see an increase in the proportion of aging, high acuity patients resulting in on-going challenges in providing person-centred, evidence-based care to patients with delirium, dementia and behavioral issues. This study evaluates the impact of a 16-hour, three-workshop program on direct care staffs' capacity, confidence, and competence in caring for patients with behavioral issues related to delirium and dementia.

Methods: A quantitative, prospective study was designed. Workshops utilized various teaching and learning modalities to foster knowledge acquisition and skill enhancement. Participants consisted of direct care staff with a background in geriatric care.

Results: A total of 75 participants completed the workshops. Paired $t$-tests were conducted for survey question scores at the alpha level of 0.05 . Ninety-five percent confidence intervals were assessed in addition to $p$-values for significance. No results were statistically significant.

Conclusions: Positive clinical significance included improved participant knowledge in dementia pathophysiology; increased awareness of the impact of care strategies on patients and families through the use of case-based application and standardized patients; and a greater integration of the concept of personhood into patient care planning.
\end{abstract}

Key Words: Geriatrics, Hospital, Teaching, Dementia, Delirium, Behavioural issues, Challenging behaviors, Educational programs

\section{INTRODUCTION}

In 2011, 15\% of Canadians 65 and older were living with some form of cognitive impairment. ${ }^{[1]}$ One of the most challenging aspects of dementia care for informal and formal care providers is that of the behavioural symptoms that accompany the disorder. Behaviours such as resistance to care and wandering, are often interpreted as abusive, socially inappropriate, and a source of elevated levels of stress and strain for nurses. ${ }^{[1-3]}$ These behaviours can also exist with delirium, a syndrome characterized by an acute change in mental state which often manifests as altered thinking and inattention. ${ }^{[2]}$
Delirium can present itself in fourteen to eighty percent of all elderly persons hospitalized for the treatment of an acute physical illness. ${ }^{[4]}$ Thus, behavioral disturbances in patients with delirium and/or dementia can have a significant impact not only on patient outcomes and healthcare system costs, but also on patient, family and staff satisfaction. This paper seeks to explore the development and impact of a pilot educational program focused on improving direct care staffs' capacity, confidence, and competence in working with geriatric patients with behavioral disturbances related to delirium and dementia.

\footnotetext{
*Correspondence: Nana Asomaning; Email: nasomaning@mtsinai.on.ca; Address: Mount Sinai Hospital, University Avenue University, Toronto, ON, M5G 1X5, Canada.
}

Published by Sciedu Press 


\subsection{Organizational readiness and needs assessment}

Located in Toronto, Ontario, Canada, Mount Sinai Hospital (MSH) is a 446 bed academic, tertiary care hospital in a downtown urban centre with a long-standing commitment to geriatric care. Approximately $44 \%$ of the medical and surgical patients are 65 years and older. In 2010, an organizational Acute Care for Elders (ACE) strategy was actualized to support the growth of geriatric initiatives, programs and structures. To better understand the needs of an educational program focused on delirium and dementia, the authors underwent a review of annual Employee \& Physician Experience Surveys and identified an increasing trend in which direct care staff were challenged with providing care to older patients with behavioral issues. In reviewing the hospital's Geriatric Institutional Assessment Profile (GIAP) Survey, available as a member of the Nurses Improving Care for Healthsystem Elders (NICHE) program, the authors were able to identify a lack of knowledge, comfort, support and structure for staff in working with older patients with behavioral issues and their family members. Hospital safety reports that focused on patient or staff harm as a result of older patient behavioural issues were also analyzed. The information from these reports identified increasingly harmful and emotionally charged situations. Based on review of the aforementioned data, coupled with the local health region and provincial imperative to improve care of older adults with dementia and delirium, the hospital's Geriatric Steering Committee committed to support innovative initiatives and solutions in improving the care of older patients with behavioural disturbances; and staff's ability and comfort in working these patients and their families.

\subsection{Workshop}

Utilizing the tools of comprehensive decision making frameworks, two Nurse Practitioners in Geriatrics developed and implemented a program consisting of 3 sequential workshops that focused on improving direct care staffs' competence, confidence and capacity in working with older patients with behavioural issues related to delirium and/or dementia. ${ }^{[5,6]}$ Workshop participants included members from the hospitalwide, inter-professional geriatric champions group and the interdisciplinary staff on the ACE unit. Both groups were chosen as the initial program attendees given their inherent interest in overall geriatric care and the high rate of exposure to the geriatric population by ACE staff in particular. Workshop format was chosen based on adult learning principles and available resources. Workshop formats used various teaching and learning modalities including didactic education, experiential and small group learning, case-based application through simulation, and the use of standardized patients (SP). In collaboration with the University of Toronto Standardized Patient Program, scenarios that mimicked real-life situations were developed for participants (see Table 1). The advantages of utilizing SPs and case based application as a form of teaching has been well supported. ${ }^{[7]}$ The use of simulation with SPs allowed participants to perform aspects of their clinical practice in a safe and non-threatening environment. ${ }^{[8]} \mathrm{In}$ contrast, role play, though more affordable, can lead to a loss of reality resulting in a less insightful overall experience. ${ }^{[8]}$

Table 1. Scenario \#1

\begin{abstract}
Opening Scenario
Tony DeLuca is a widowed 83 year old man who lives alone in a Senior's Residence. He is a retired musician and since, has taught music to children with special needs. Tony’s niece, Helen visits regularly.

Tony was sent to the hospital yesterday afternoon after other residents at the Retirement Home found him acting "bizarre" and "yelling at nothing”. One of the tenants called 911 after Tony fell trying to open the door of an apartment that was not his. In the ED, Tony was verbally and physically aggressive requiring restraints and antipsychotic medications.

When he comes up to your unit Tony is difficult to rouse. You do not have any baseline information as he has been too drowsy to obtain any. As your shift progresses Tony becomes more alert. As you go in to assess Tony, you find he is not in his room. Instead, Tony is in the hallway trying to open the door that takes him to the elevators.
\end{abstract}

Participant's Task:

Re-direct Tony back to his room. You have 10 minutes to complete task. 
Each of the three workshops focused on different areas of education and skill development (see Table 2). The objective of workshop 1 was to improve knowledge related to dementia, delirium and associated behaviors. Field experts on topics ranging from Personhood to the Confusion Assessment Method (CAM) were invited to deliver content. The objectives of workshop 2 were to improve skill, ability and confidence in responding to behavioural disturbances. The Gentle Persuasive Approaches (GPA) for Dementia Care curriculum was used to meet these objectives. Lastly, the focus of workshop 3 was to apply knowledge learned in workshops 1 and 2 through SP use and to gain confidence by applying this knowledge.

Follow up post workshops was dependent on whether participants were members of the inter-professional geriatric champion group or ACE unit staff. As part of their membership requirements, the former was required to attend a pre-scheduled meeting to highlight clinical cases, provide organizational geriatric-related updates, and build mentoring skills. The ACE unit staff continued to build strength in capacity and confidence with mentorship from the unit's Geriatric Nurse Practitioner and the hospital's Geriatric Psychiatry Clinical Nurse Specialists.

Table 2. Workshop overview

\begin{tabular}{|c|c|c|c|}
\hline & Workshop 1 & Workshop 2 & Workshop 3 \\
\hline Objective & $\begin{array}{l}\text { To improve knowledge } \\
\text { related to dementia, } \\
\text { delirium and associated } \\
\text { behaviours }\end{array}$ & $\begin{array}{l}\text { To utilize a pre-developed and widely used curriculum to } \\
\text { improve skill, ability and confidence in responding to } \\
\text { responsive behaviours. } \\
\text { • } \quad \text { Gain understanding that each person with dementia is a } \\
\text { unique human being who is capable of interacting with } \\
\text { the outside world } \\
\text { Explore a holistic perspective to explain the relationship } \\
\text { between the disease process and the person's behavioral } \\
\text { response } \\
\text { Apply emotional, environmental, and interpersonal } \\
\text { communication strategies that diffuse challenging } \\
\text { behaviours } \\
\text { Respond with the suitable and respectful protective } \\
\text { techniques to use in response to catastrophic behavior } \\
\text { Evidence-based, } 7.5 \text { hour curriculum consisting of } 4 \\
\text { modules }\end{array}$ & $\begin{array}{l}\text { To apply knowledge learned in } \\
\text { workshops } 1+2 \text { to "real life" } \\
\text { situations in a non-threatening and } \\
\text { safe environment that fosters } \\
\text { feedback and sharing of experiences }\end{array}$ \\
\hline $\begin{array}{l}\text { Teaching } \\
\text { Modality }\end{array}$ & - $\quad$ Didactic & - $\quad$ Didactic and case based & $\begin{array}{ll}\text { - } & \text { Standardized patients } \\
\text { - } & \text { Case scenarios }\end{array}$ \\
\hline Content & $\begin{array}{l}\text { - } \quad \text { Personhood } \\
\text { Cognitive } \\
\text { Disorders \& } \\
\text { Challenging } \\
\text { Behaviours in } \\
\text { Acute Care } \\
\text { Caregiver } \\
\text { Supports } \\
\text { Documentation }+ \\
\text { Communication }\end{array}$ & $\begin{array}{l}\text { - } \quad \text { Overview of principles of person-centred care } \\
\text { - } \quad \text { Meaning behind responsive behaviours exhibited by } \\
\text { persons with dementia } \\
\text { - } \quad \text { Introduction to impact of dementia on the brain } \\
\text { - } \quad \text { Apply emotional, environmental, and interpersonal } \\
\text { communication strategies that diffuse responsive } \\
\text { behaviours } \\
\text { Suitable, respectful self-protective and intervention } \\
\text { techniques to use in response to catastrophic behavior }\end{array}$ & $\begin{array}{l}\text { Four case studies developed from a } \\
\text { needs assessment and expert opinion } \\
\text { 1. Verbal and physical agitation; } \\
\text { potential for physical aggression } \\
\text { 2. Emotional support and family } \\
\text { education on dementia and associated } \\
\text { behaviours } \\
\text { 3. Baseline history and assessment } \\
\text { skills } \\
\text { 4. Inter-professional communication }\end{array}$ \\
\hline
\end{tabular}

\section{Study Methods}

This study used a quantitative, prospective study design. Opportunistic sampling was used in which available participants guided sampling decisions and chose to participate based on independent interest or area of employment. ${ }^{[9]}$ Participants were recruited from September 2012 to December 2012. Inter-professional geriatric champion group members were solicited by email and asked to join on a voluntary basis as either new or returning members. Staff on the ACE unit participated in all workshops as part of their annual skill

Published by Sciedu Press development requirements. Inclusion criteria for participants were any Registered Nurse (RN) or Allied Health member (Physiotherapist, Occupational Therapist, Respiratory Therapist, Dietitian, Pharmacist, Speech Language Pathologist, etc.). The only exclusion criteria were students and physicians. Participants were expected to attend all three workshops which were offered three to four times per month over the course of four months. Mount Sinai Hospital Research Ethics Board approval was obtained.

General Workshop evaluations and Knowledge and Self- 
Efficacy Surveys were used to evaluate the program. Selfefficacy relates to a participant's personal belief in their ability to produce a given outcome ${ }^{[10]}$ and was assessed to better understand the workshop impact on staffs' confidence.

\subsection{Evaluation}

Participants took part in evaluation activities over the course of six months; there were no incentives offered for evaluation completion. Knowledge and Self-Efficacy Surveys were completed at 0 and 6 months. In the Knowledge Survey, the true/false questions were separated from the matching questions as they each informed different areas of Knowledge that the investigators were interested in analyzing separately. The True/False questions dealt with misconceptions associated with delirium, dementia, and challenging behaviours. The matching section dealt specifically with the 7 A's of dementia defined as the different symptoms associated with the disorder as a result of a pathology to different parts of the brain. ${ }^{[11]}$ At 0 months, both surveys were distributed and collected at the beginning of the first workshop, prior to content delivery. Six months after completion of all workshops, surveys were sent to participants via an online survey software email. To encourage survey completion at this time, email reminders were sent to participants every week for 3 weeks. Only participants who completed both pre and post workshop surveys were used in post-workshop analysis (see Figure 1). General workshop evaluations focused on process and structure such as mode of content delivery (see Table 3 ). This was completed at the end of each session in paper format. During workshop 3, notes and general comments were also collected on staff-to-staff, SP-to-staff, and facilitator-to-staff dialogue.

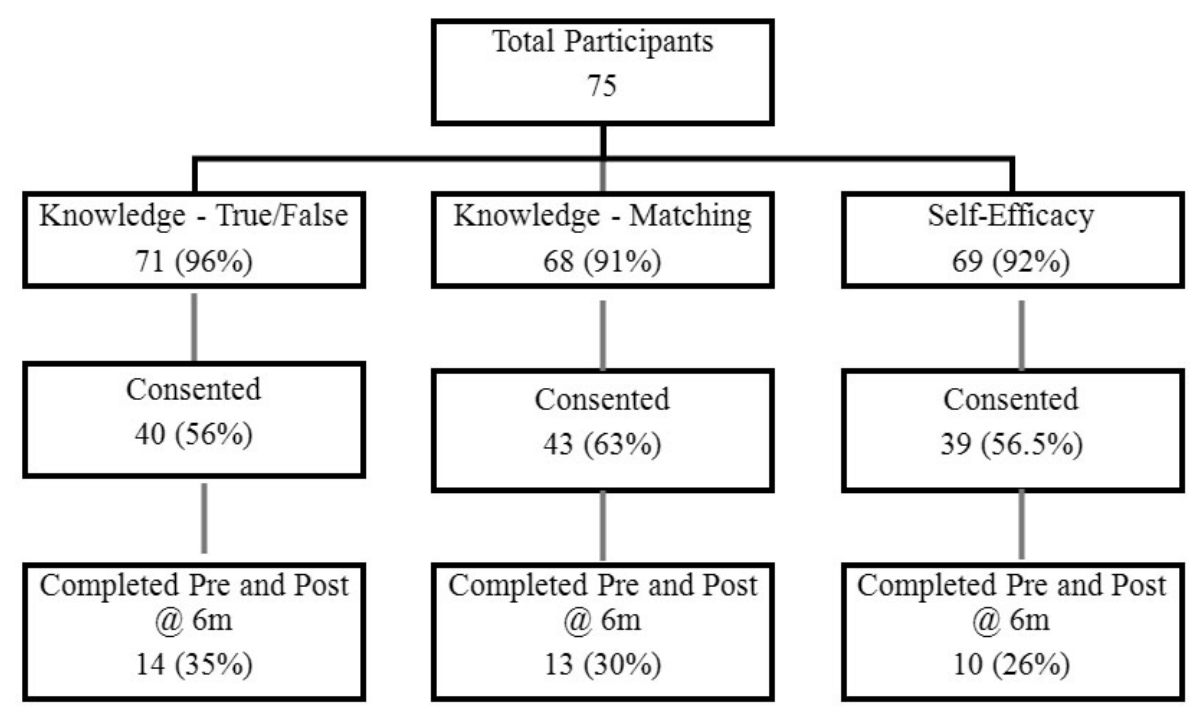

Figure 1. Flow diagram showing response rates (\%) of knowledge and self-efficacy surveys

\subsection{Statistical analyses}

Data analysis was done by a Research Assistant using SAS version 9.3. Paired $t$-tests were conducted for survey question scores at the alpha level of 0.05 . Ninety-five percent confidence intervals were assessed in addition to $p$-values for significance.

\section{RESUlts}

Seventy-five participants attended the program workshops. Forty participants consented to the complete the Knowledge Survey. Of these 40, the survey score at 0 months was $81 \%$. As an example, thirty-seven percent of these participants accurately responded to the question, "Psychotropic medications are helpful in treating behaviours such as pacing, repetitive verbalizations (e.g. 'help, help, help') and climbing out of bed".

Fourteen of the 75 participants completed the true/false Knowledge Survey at 0 and 6 months (see Table 4).

Within this group, individual scores stayed the same or had modest decline. The average score for the question, " $\mathrm{Hy}$ poactive delirium isn't as serious as hyperactive delirium”, improved from $93 \%$ to $100 \%$. The average matching score of the Knowledge Survey at 0 months was $60 \%$. Only $35 \%$ of participants knew the correct definitions of anosognosia (lack of insight or awareness) and agnosia (inability to recognize common objects). The correct match for the definition of anosognosia improved to $79 \%$. 
Table 3. Sample workshop evaluation

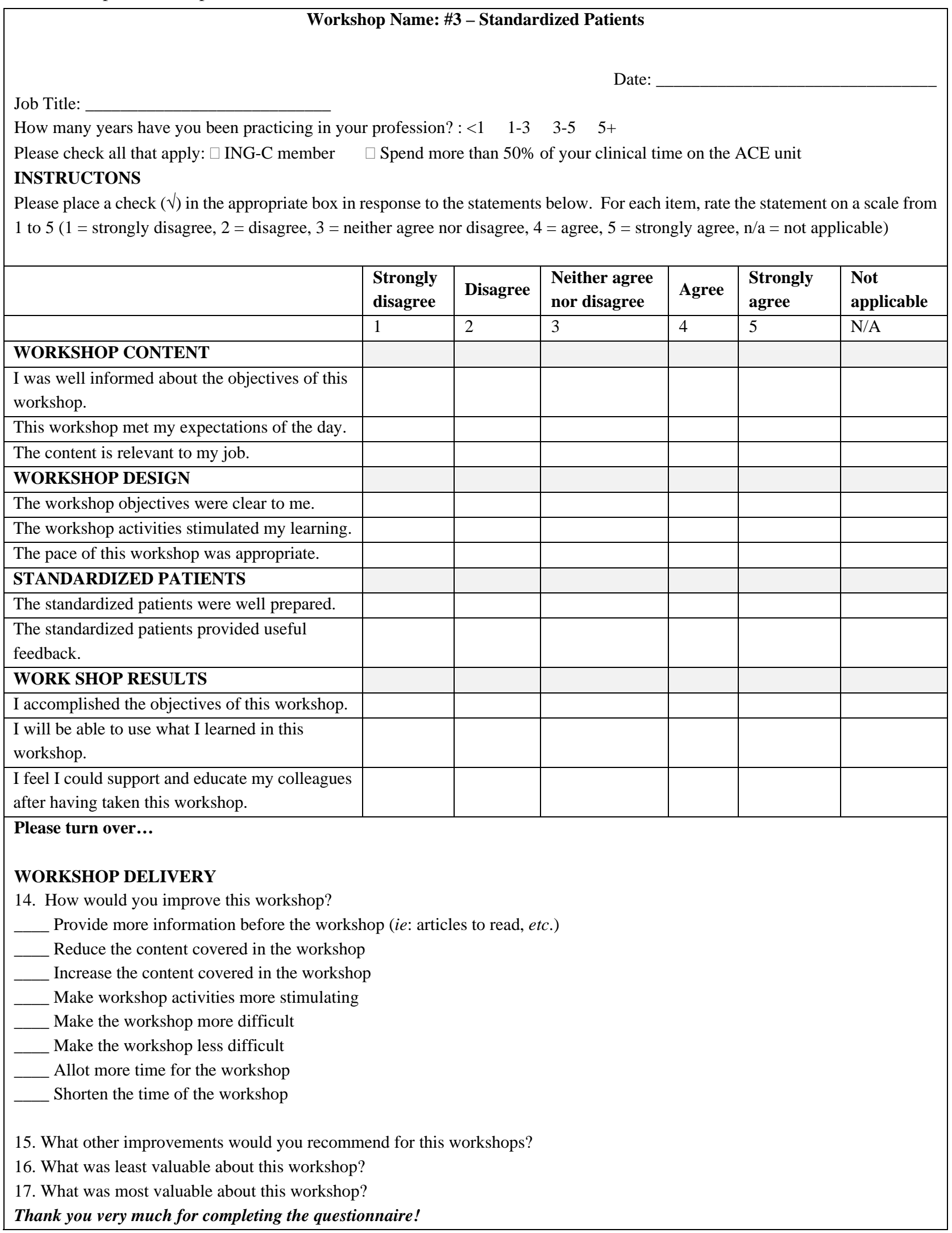


Table 4. Average survey score for participants at 6 months versus 0 months

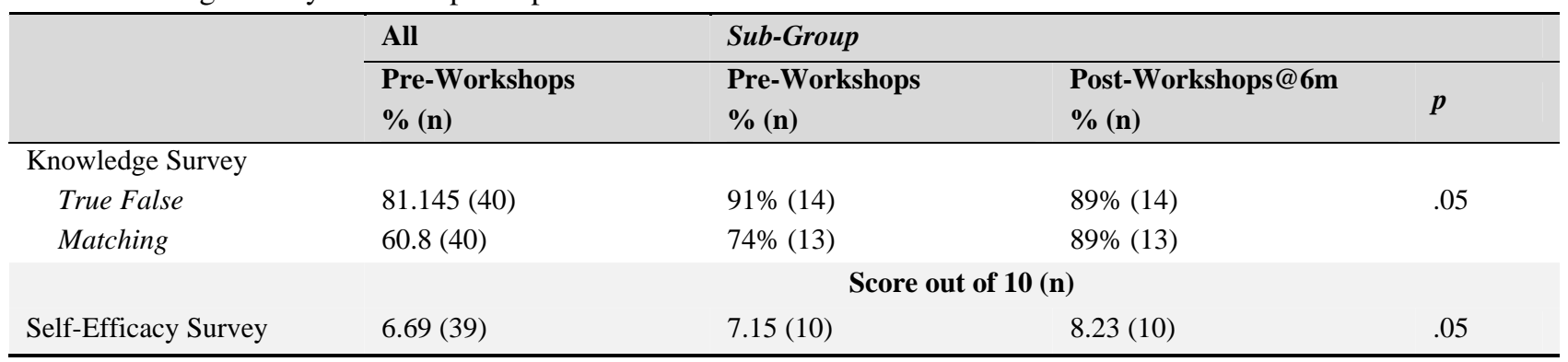

Thirty-nine participants consented to the Self-Efficacy Survey. Of these, the survey score at 0 months was 6.69 out of 10. Ten of the 39 participants completed the Self-Efficacy Survey at 0 months and 6 months. Of this sub-group, scores improved from 7.15 to 8.23 out of 10 . The average score for each individual criterion on the scale also improved within this group. The question, "Incorporating a patient's unique history into their care plan", had the most improvement at 6 months. Due to a small n-value for all surveys, the change in results did not prove to be statistically significant.

With respect to evaluation of the individual workshops, criteria averaged a score greater than 4 out of 5 . Feedback from participants indicated preference for more pre-workshop reading material; full day versus half-day workshops; and more interactive engagement (less didactic). Overall, participant comments highlighted their satisfaction with the program and felt it offered valuable learning experiences.

As noted in the debriefing sessions of workshop 3, the use of SPs allowed participants to gain an increased appreciation and understanding of the impact their existing strategies have on patients and their loved ones; and the ability to see the patient as a whole person rather than their behavioral issue alone.

\section{Discussion}

In acute care, direct care clinicians acknowledge a need for greater education in dementia care. ${ }^{[12]}$ The development and implementation of this program highlighted important facilitators and challenges to delivering such an educational curriculum in an acute care setting. A key facilitator was organizational interest and support. This was achieved by aligning the program with existing internal initiatives such as the inter-professional geriatric champions group and developing learning objectives based on identified care and knowledge gaps. For example, hypoactive delirium, which is the most common form of delirium, and is frequently missed or misdiagnosed, was highlighted as a significant learning opportunity. ${ }^{[13]}$ Though statistically insignificant, there was a noted improvement in the knowledge criterion related to hypoactive delirium post workshop implementation.

The knowledge questions with the greatest improvement were related to the definitions of anosognosia and agnosia, which contribute to a patient's judgment and overall function. ${ }^{[11]}$ The acquisition of this knowledge by a workshop participant may assist in their ability to gain a better understanding of challenging behaviours and the limitations associated with behaviours that are likely in response to inaccurately perceived stimuli. ${ }^{[14]}$

Apart from an increased understanding of dementia and its connection to behavioural disturbances, the multi-formatted approach of the program also had a positive impact on participants' self-efficacy; albeit not statistically significant. In light of this, program developers would benefit from being cognizant of the fact that an intent or personal judgment of capability is different than an actual ability. ${ }^{[10]}$ Workshop 3 which included the use of Standardized Patients, provided any opportunity for participants to reflect on challenges that may have an impact on how they respond to a situation in a real life setting. ${ }^{[10]}$ The use of role play as an alternative approach should be considered if organizational resources are unable to support the use of SPs.

Notwithstanding the program content itself, using a comprehensive decision-making framework allowed for the examination of key considerations including stakeholder buy-in, setting attainable goals that aligned with existing macro and micro level initiatives, and securing financial assistance. ${ }^{[5]}$ Important pragmatic elements included the provision of each workshop on multiple days so that participants were given the opportunity to find a day that worked with their schedule, seek shift coverage, and work with nursing unit managers to plan staffing ahead of time. Lastly, support from the Senior Director responsible for the units participating in the program created visibility and confidence in the program. This support was primarily to backfill nursing staff to free up participants to attend the program; compensation for participants to attend the workshops; and miscellaneous program expenses. 
As with many initiatives centered on direct care staff, it proved time consuming to ensure staff signed up for workshops despite their identified interest in attending. Survey completion was another challenge which may have been the result of survey fatigue and lack of appreciation for the research component of the program. Another significant limitation was the time and effort needed to organize and facilitate the workshops. Similar challenges were found in designing a training program geared at improving staff attitudes in an acute care setting. ${ }^{[6]}$ As such, any program of this scale would benefit from dedicated human resources to focus on workshop development and implementation.

\section{Study limitations}

A major study limitation was the format of follow-up evaluation. The Knowledge and Self-Efficacy Surveys at 6 months were completed via an online survey. Participants could potentially search for answers on the internet as they completed the survey. Repeat testing bias may have been present if subjects were able to recall previous questions and answer differently based on something other than the intervention itself. The Knowledge and Self-Efficacy Surveys were only assessed for face validity; no other validity testing was completed which may have resulted in information bias. The use of ACE staff may have resulted in participants that are already geriatric-trained resulting in selection bias. The majority of participants had some previous geriatric training and inherently had a higher knowledge base in geriatrics at the onset. This may have contributed to the modest increase in post-test results. Participants who completed the follow-up survey were a small subset of the total attendees, which re- sulted in insufficient power to support statistical significance. As this program was an initial pilot of a multi-formatted education design, future studies with a larger sample size is recommended to validate results. Lastly, demographic data was not collected which may have been useful in comparing participants who consented to the study versus those who did not, to gain a better understanding of the low attrition rate at 6 months.

\section{Conclusion}

Developing a program aimed at improving the competence, confidence and capacity of direct care staff in an acute care hospital caring for older patients with behavioral issues using a structured methodology, guiding framework, and evidenceinformed approach resulted in a multi-modal education series. Results lacked power for statistical significance; however pragmatic, positive clinical significance was achieved. This clinical significance included improved participant knowledge in the pathophysiology of dementia and how the brain is affected by illness; an increased awareness and understanding of the impact of various care strategies on patients and loved ones through the use of case based application and SPs; and a greater integration of the concept of personhood into patient care planning. Further evaluation is needed on the long term impact of workshop-based education in improving the confidence, capacity and competence of participants with a focus on sustained, positive impact on practice.

\section{CONFLicts OF INTEREST Disclosure}

The authors declare that there is no conflict of interest.

\section{REFERENCES}

[1] Alzheimer's Society Ontario.. Facts about dementia. 2012. Available from: http://www.alzheimer.ca/en/on/About-dementia/ Dementias/What-is-dementia/Facts-about-dementia

[2] Health Quality Ontario. Health Quality Ontario Long-Term Care Responsive Behaviours. 2014. Available from: http: //qualitycompass.hqontario.ca/portal/long-term-car e/Responsive-Behaviours?extra=print\#. VW3SqJM005I

[3] Donnell SM, Timmins F. A quantitative exploration of the subjective burden experienced by nurses when caring for patients with delirium. Journal of Clinical Nursing. 2012; 21: 2488-2498. PMid:22784045 http://dx.doi.org/10.1111/j.1365-2702.2012.04130.x

[4] Foreman MD, Wakefield B, Culp K, et al. Delirium in elderly patients: An overview of the state of the science. Journal of Gerontological Nursing. 2001; 27(4): 12-20. PMid:11915152 http://dx.doi.o rg/10.3928/0098-9134-20010401-06

[5] Behavioral Supports Ontario. Behavioural education and training supports inventory (BETSI): A decision making framework. 2012. Available from:
http://www.hnhblhin.on.ca/uploadedFiles/Public_ Community/Our_Priorities/BSO_Project/BETSI\%20Decis ion $\% 2$ Making $\% 2$ Framework $\% 20$ June $\% 202012 \% 20$ FINAL . PDF

[6] Crabtree J, Mack J. Designing a training programme to improve staff attitudes towards people with dementia. Nursing Times. 2010; 106: 14-16. PMid:21287844

[7] Fallowfield L, Saul J, Gilligan B. Teaching senior nurses how to teach communication skills in oncology. Cancer Nurse. 2001; 24: 185-191. http://dx.doi .org/10.1097/00002820-200106000-00004

[8] Donovan T, Hutchison T. Using simulated patients in a multiprofessional communications skills programme: Reflections from the programme facilitators. European Journal of Cancer Care. 2002; 12: 123-128. http://dx.doi.org/10.1046/j.1365-2354.20 $03.00394 . \mathrm{x}$

[9] Russell C, Gregory D, Ploeg J, et al. Qualitative research. In A DiCenso, G. Guyatt, \& D. Ciliska (Eds). Evidence-based nursing. A guide to clinical practice. Philadelphia: Mosby; 2005. 120-136. PMid: 15729644

[10] Bandura A. Guide for constructing self-efficacy scales. In F. Pajares 
\& T. Urdan (Eds.). Self-efficacy beliefs of adolescents. Greenwich, CT: Information Age Publishing; 2006. 203-337.

[11] Alzheimer's Society Ontario. Seven A's of dementia. 2015. Available from: http://www.alzheimer.ca/en/york/About-dem entia/What-is-dementia/Seven-A-s-of-dementia

[12] Douglas-Dunbar M, Gardiner P. Support for carers of people with dementia during hospital admission. Nursing. Older People. 2007; 19(8): 27-30. PMid:17972782 http://dx.doi.org/10.7748/n op2007.10.19.8.27.c6269
[13] Fong TG, Tulebaey SR, Inouye SK. Delirium in elderly adults: Diagnosis, prevention and treatment. Nature Reviews Neurology. 2009; 5: 210-220. PMid:19347026 http://dx.doi.org/10.1038/nrneu rol.2009.24

[14] Murray Alzheimer Research and Education Program. Responsive behaviours. 2007. Available from: https://uwaterloo.ca/mur ray-alzheimer-research-and-education-program/resea $\mathrm{rch} /$ projects/responsive-behaviours 